\title{
Emergence of Cultural and Fashion Uniqueness from Bihar (India) Rooted in Its Distinctive Regional Background
}

\author{
Vinayak Yashraj $^{1}$, Priyanka Tripathi ${ }^{2}$ \\ ${ }^{1}$ Department of Fashion \& Lifestyle Accessories, National Institute of Fashion Technology Patna, Patna, India \\ ${ }^{2}$ Department of Humanities and Social Sciences, Indian Institute of Technology Patna, Patna, India
}

Email address:

vinayak.yashraj@nift.ac.in (V. Yashraj), priyankatripathi@iitp.ac.in (P. Tripathi)

\section{To cite this article:}

Vinayak Yashraj, Priyanka Tripathi. Emergence of Cultural and Fashion Uniqueness from Bihar (India) Rooted in Its Distinctive Regional Background. American Journal of Art and Design. Vol. 3, No. 3, 2018, pp. 26-32. doi: 10.11648/j.ajad.20180303.11

Received: October 31, 2018; Accepted: November 16, 2018; Published: December 14, 2018

\begin{abstract}
This paper studies the state of Bihar, India from the perspective of its distinctive regional background and social cultural milieu. It articulately outlines the emergence of artistic and cultural uniqueness reflected in its people, having common sets of values, social moorings, moral and mythological stand points; styles of adornment through attires, body art, textiles, cosmetics, accessories, which not only gives them a distinctive identity from the rest of the nation and globe at large but also catalyzes the process of shaping the individualistic and divergent regional fashion and aesthetic uniqueness. Not only does this distinctive identity goes on to constitute the language of regional fashion but it transforms the understanding that fashion is not merely western or Euro centric but it also breaks the binary of "west versus the rest". Historically, Bihar had been the place from where the struggle for Indian Independence was initiated by freedom fighters like Gandhi from west Champaran trough the indigo revolution, and thus the symbols of this struggle, like khadi got integrated as a prevalent fabric for dressing up in the region. The paper through the lens of identity, looks into how this nationalistic look related to freedom struggle goes on to becoming the face of a segment of people. The paper also, with a feminist framework, analyses, the married women of Bihar who primarily form the important strata of this state's society and represent it distinctively vis-a-vis other sections of women from other geographical parts of India. The research paper semiotically studies through secondary research method the different symbolism intricately connected to the identity of the Bihari women and men with elements connected to adornment and dressing up. That both khadi and the ethnic Bihari elements of dressing up of men and women is being explored as a raw material by Indian retail brands in a sense to bring culture to the realm of economics and fashion system by challenging the western models of fashion monopoly and Euro centrism.
\end{abstract}

Keywords: Identity, Regional Fashion, Socio-cultural Context of Bihar, Khadi, Adornment

\section{Introduction}

Speaking from a social cultural point of view, people from any specific region and in this research article in context of Bihar, will largely give a collective unity in terms of their shared beliefs, sets of values, social moorings, and how they have been given down the heritage of history, events from the past and the distinctive amalgam of folk, legends and acquired traditions. The people found in this specific region can be further divided in to segments comprising of individuals having common cultural binding. Being part of a country which boasts of its immense diversity, Bihar has added on to this uniqueness of India in its own unique mode, and is representative of an ethos which shapes the philosophy and identity of the groups of people, who are rooted here.

Having its origin in the Indo Aryan ethnic group and a history which is three millennia old Bihar is distinctly one of the largest states of India. The pacifist religious icons of the globe like the Buddha and the Mahavira have been nurtured here apart from the glory of the two dominant empires - the Mauryas and the Guptas in the Magadha region. Bihar has been the cradle to one of the oldest universities and an array of historically and culturally prominent intellectuals and art forms emanating from its environment symbolising Bihari culture, like the crafts of madhubani, manjusha, sujni, sikki to name just a few. This state or region has some very unique and vibrant festivals, customs, way of life rooted in its 
agrarian life.

Till the nineteenth century and the early part of the twentieth century Bihar was part of the Bengal Presidency and under its influencing dominance and control. This had an everlasting impact on the conditioning of people of Bihar where, intellect, rituals, customs, language etc influenced the people of Bihar immensely specially seen in the district of Darbangha. Bihar rose to a position of eminence as it was in Bihar that Mahatma Gandhi launched his foremost social experiments through the Champaran Satyagrah in the wake of the atrocities faced by the farmers at the hands of the British. Quit India Movement and the JP Movement also became the part of the socio-political movements in Bihar.

These historical realties which this region of Bihar has gone through had a indelible impression on the culture and mindsets of the communities, groups of people, urban tribes of Bihar at large. As discussed by some of the sociologists, culture has been defined as the sum total or the assemblage or collection of practices, which is handed down or inherited and it shapes up the social fabric of the lives of people of a certain region [5]. Bringing this understanding into the ambit of the socio - cultural milieu of Bihar which is very representative of its unique civilisation. Not only in the way the people's values or beliefs have shaped but adding to it, also the way they go through the events of life like birth, marriage, occasion, celebrate festivals or perform rituals. What constitutes essentially as the Bihari culture and identity is a complex set of socially transmitted set of artistic, social, philosophical, customary pattern of actions over the ages.

This article attempts to find out as to how a distinctive regional background and social cultural milieu, formed through the basis of elements of artistic and cultural uniqueness like common sets of values, social moorings, moral and mythological stand points; styles of adornment through attires, body art, textiles, cosmetics, accessories; helps formulate a specific identity for its sections of people in comparison to the rest of the nation and also the word at large. Taking it forward the article also investigates as to how this uniqueness also helps constitute the individualistic and divergent regional fashion and aesthetics and through the research it is understood that fashion is not merely western or Euro centric and breaks the binary of "west versus the rest".

Applying the lens of identity, the paper looks into how the nationalistic look related to freedom struggle goes on to becoming the face of a segment of people. The paper also, with a feminist framework, analyses, the married women of Bihar who primarily form the important strata of this state's society and represent it distinctively vis-a-vis other sections of women from other geographical parts of India. Using the theories of semiotics the paper studies through secondary research method the array of symbolism intricately connected to the identity of the Bihari women and men with elements connected to adornment and dressing up. The paper examines as to how khadi and the ethnic Bihari elements of dressing up of men and women is explored as a raw material by Indian retail brands in a sense to bring culture to the realm of economics and fashion system by challenging the western models of fashion monopoly and Euro centrism.

\section{The Bihari Milieu and Culture}

\subsection{The Bihari Identity}

Within the gamut of identity theories it is posited that the individuals in society assert or maintain their specific identity in context to their roles, objective and status in society, groups or sections. Identity is represented through fashion where identity could infer to dimensions of nationality, region, race, ethnicity, place, class, gender, sexuality, broadly under the sphere of society and culture. In context of studying culture in relation to the regional-nationaltransnational, and in relation to fashion, it is understood that just like nations and regional states are politically formed so is fashion also formed and created. In an attempt to interpret identities from socio-cultural perspective a whole array of meaning and inferences can be analysed and deduced pertaining to people in background of region and place as well. The inimitable and distinct culture of Bihar is the way in which different groups or segments of people in Bihar adorn and formulate a identity for themselves which symbolically disseminate a rich plethora of meanings which can be understood with the lens of semiotics and cultural studies in the perspective of this region. When the array of styles of adornment and dressing up is enquired a lot of meanings is derived which gives root to the understanding of what constitutes fundamentally as the Bihari identity. The paucity of research in this area leads to the realization of the need to investigate as to how adornment and dress is closely linked to one's regional culture and how it forms the distinctive identity in terms of its fashion and in the context of this research, it is Bihar.

\subsection{Sociological Perspective of Identity in Context to Dressing $U p$}

It is pertinent to bring to fore some of the elements of the studies of sociology and culture to examine this context of regional fashion clearly, and how inextricably these theoretical insights are associated to adornment and dressing up. As posited by sociologists like Georg Simmel [4], that through dress messages are disseminated and the dress which has evolved from the process of sociological changes and is the mirror of the social background of the wearer. In the zone of the dress and culture, as formulated by Eicher and Roach Higgins, [16], to communicate identity, dress disseminates an amalgam of meanings in context of self, social structure, beliefs and values and the information could stretch from age, gender to religion and from demographics, political affiliations, religion to personality and psyche of the wearer. Going by the insight given by Neil Howe [17], putting together what constitutes the material and the non material aspects of culture including clothes, adornment, books, habitat in the former and values, customs, language in the later, culture can be defined as something, that remains part of the society through ages and is indispensable to the 
existence of individuals.

\subsection{The Tempo Spatial Aspect of Fashion}

Discussed in the book by Susan B. Kaiser, titled Fashion and Cultural Studies [19], the author posits through the opening paragraphs that fashion does not definitely have anything quintessentially very core to it and that it is something which goes through a gradual but a definite social process of discussion and change to be arrived at something in future. It is also a collective phenomena and it is shaped up as humans move through time and space. These two entities of time and space seem to be conceptual, ambiguous and intangible. It becomes imperative to decipher and articulate who we are and to also articulate when and where we are. The author further posits that:

"Fashion is never finished, and it crosses all kind of boundaries. It is ... visual and material interpretations of who he or she is becoming and how this connects with other's interpretations ... it involves mixing, borrowing, belonging, and changing. But it is also about matching, creating, differentiating, and continuing." Susan B Kiaser.

As taken up in this particular research article this understanding when applied to the region of Bihar can be viewed in context of two sets or groups of people and seen as to how the socio cultural milieu has shaped up the values, beliefs, norms, adornment, dress, clothing of these two sets of people, their by creating a distinct identity of the mentioned groups and of the region of Bihar at large.

\section{The Socio-Politico Section of Bihari Men}

\subsection{To Conform and to Distinguish for Distinctiveness}

The first set of people that comes in to reference is the one which aligns itself strongly to being associated to the political class and doesn't shy away from showing their affiliations to the political class with an overall general look similar amongst the larger number of people of this group or the tribe with certain peculiarities being distinctive in context of the type of the political party the individual is adhering to. This duality in the psyche is that it is to in one way conforming to and following the accepted norms and codes of dressing up as the characteristics of the group that they affiliate to at large and on the other to distinguish themselves earnestly within the same group and assert one's further sub affiliation or personalisation of the dress. Bringing in from the insights of Fred Davis, [7], its largely understood that dressing up is a lens through which one can analyse in detail aspects about what the wearer wants to display and reveal but at another level it can also be analysed with erudite depth as to what the wearer is choosing to hide and disguise. This dual nature of clothing gives it a potential to represent identities to communicate array of meanings on one side and also camouflage certain other aspects of the personality. The objective of this research is to situate how these tribes can be placed in the tempo spatial context there by creating an understanding of regional fashion, distinctive from the national or the western sense.

\subsection{Semiotics of Symbols}

The uniqueness can be adjudged from the overall mix of their thought process, ideologies, approach to life, body language, demeanour, linguistic tone, to more tangible aspects like their dress, adornment, hair do, facial characteristics derived from the style of hair, beard, religious or cultural insignia, footwear, choice of fabrics and colours. When seen largely as a whole, these formulate a set of signs denoting volumes about the background of this tribe and vast amount of knowledge. In the sphere of semiotics, the theories of Ferdinanad De Saussure explains that when clothing is taken up as a structure and scheme of language emanating sense and implying something then it is of utmost importance to research the link of the signifier that is the characteristics of the dress and the signified as the meaning that it creates.

To appreciate the understanding of the importance of why symbols are created, viewed through the lens of semiotics and to go into its roots in the Indian context it is relevant to bring forward the ideas articulated by Asit K Haldar in his article titled "Symbolism in Indian Art and Religion". Haldar conjectured through this article that if viewed historically and going back to the Vedic times, hymns were created to exemplify the observations made by the raw mind of the wonders of nature beyond the explanation and comprehension of the uncouth man. Through these hymns, comprising of symbols, humans made a fair attempt to bring them within the confines of their mental grasp. He goes on to elaborate:

"In both Vedic and Puranic periods our sages accepted the inevitable power of sense-perception, Rasa-bhava, and explained eternity and existence by interpreting various symbolical patterns and images including deities ... Hymns objects typifying or representing things of resemblance; later on these grew into multifarious symbolical representations" [3].

\subsection{Decoding the Symbols}

When these understandings are applied to this tribe comprising of Bihari men with political affiliations, one can particularly see a pattern of symbols and decode them easily in perspective of the socio cultural context. The clothes that this group wears, comprising of Indian garments like kurta, waist coat, stole, churidaars, pyjamas, Gandhi topi, in mostly khadi or certain similar types of fabric in handloom, handmade or cotton brings close to the memory that this group connects to the idea of politics for societal, progressive change and development as exemplified by the likes of Gandhi. That khadi is the political symbol and material embodiment of the national struggle and accomplished device to bring diverse people together to represent the lofty socio-political ideals of national integration and self-reliance [20]. In a sense the people adhering to these sets of values 
always come together to form a tribe and specially so in the environment of Bihar and become one strong visible entity. Sometimes in the hands of this influential tribe it becomes a means for the projection for patriotic fervour too.

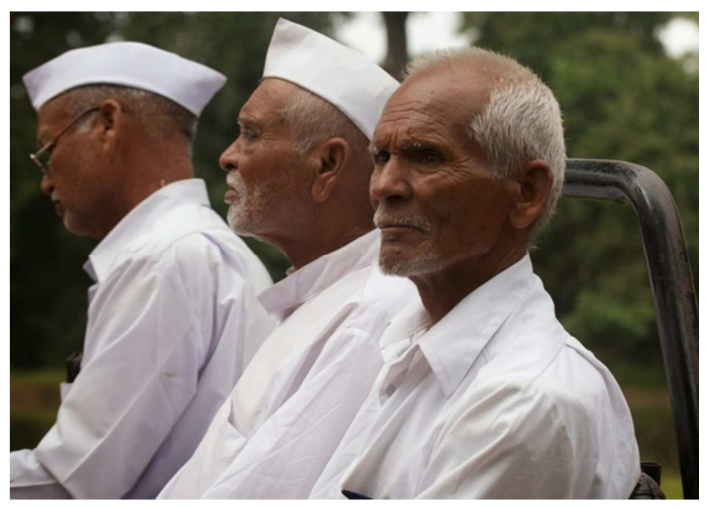

Figure 1. Men from this socio-politico tribe seen here with material codes like the Gandhi topi, khadi kurta. [8].

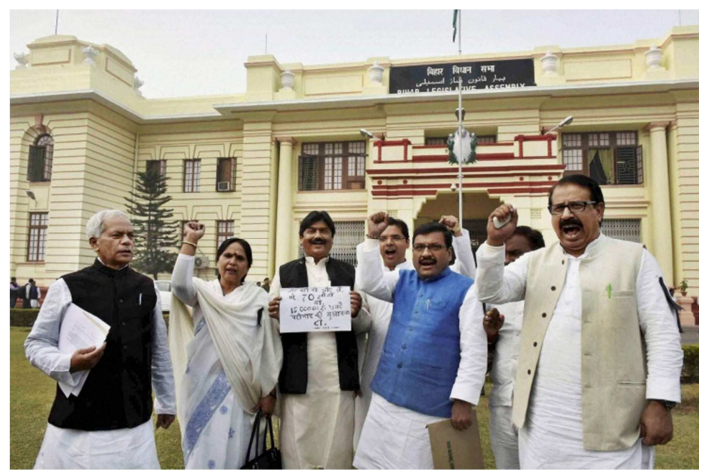

Figure 2. Elements of tangible adornment in khadi and in certain styles disseminate sets of meaning identifiable to a possible section from the region of Bihar. [9].

\section{The Married Women, Governed by Religion and Customs}

\subsection{Formulating Identity and the Lens of Feminism}

The research paper explores the socio-cultural dimensions of another segment in context of Bihar, that of the middle aged, married women who are deeply and culturally engrained in this region in terms of their religious, ethnic, customary guidelines and abide by them. Looking at it from the feminist framework, there seems to be a clear domination of patriarchy and strongly hints at unequal status of women in the society. This brings to fore a group of women visible by their acceptance of certain material codes, adornment and dressing up to establish a definitive identity based on societal norms to uphold the masculine supremacy. This specific tribe entrenched in their societal moorings adhere to the forms of adornment, dressing up, body transformation, make up to referentially indicate to the world around, about their inclination and the pleasure derived in adorning themselves in the realm of art and culture in a certain time. For instance according to Eicher, religious guidelines on adornments, dressing etc are there in religious texts formulated in medieval times [18], similarly, it is posited by Emma Tarlo in her book "Clothing Matters" [6], that clothing and adornment evolve within the cultural religious context of a region. Further, in his article titled "Ornament", Ananda K Coomaraswamy explains the meaning of ornament by going into the roots of the Hindi word alamkara [1], where its use is of rhetorical nature for the application of enhancing figures of speech, or in the case of jewellery, for enhancing the human body, and thereby employing it for effective and resonated communication.

\subsection{The Amalgam of Feminine Adornment: A Feminist Perspective}

The women in Bihar are known to be using such ornaments like the bichiya (toe ring) and other decorative make up like the bindi ( red dot on forehead) or the tikuli (the art of making red dots), sindoor (vermilion on the central hair parting on the forehead), alta (red coloured foot beautification art) and godna (a traditional body tattoo art). Most of these again depict the women's association with their identity as married women. It in a way, signifies the women's position in society in relation to her male partner and never independent of it. Apart from this there are crafts like sujni (a textile recycling craft). Sujni has also in recent times given a symbolic platform for women to create narratives through its motifs about the concerns of women, their struggles, and issues. Most of the elements of adornment mentioned have one thing in common that they are the material marker for the married women and connote to a certain stage in the women's lives and have a distinct Bihari ethnic identity attempting to break the binary of native versus the modern and ethnic versus the global [21]. Few elements like the alta and sujni have a strong link with the influence of Bengal on the cultural life of Bihar.

A bichiya or a toe ring signifying married woman is available in variety of designs and is generally made in silver and worn on the toes of the feet. It is assumed through religious and Vedic scriptures that bichiya has healing power.

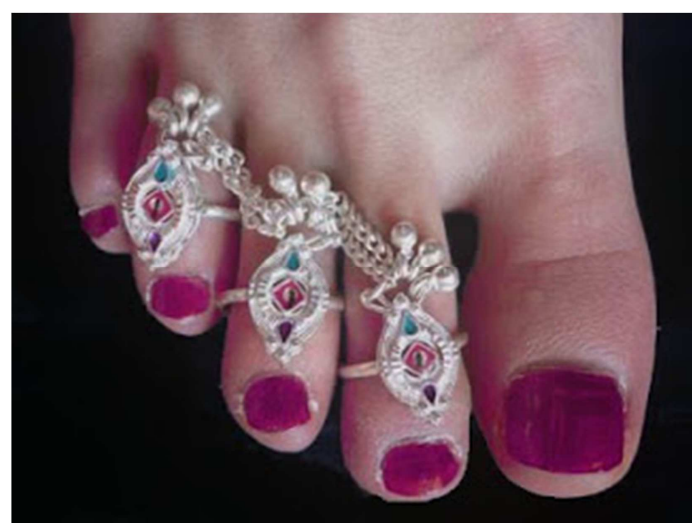

Figure 3. Bichiya, or the toe ring, is generally worn by women during marriage and then later becomes part of the daily wear. It is worn during rituals too. [10].

Another marker connected to marriage is the bindi 
meaning a dot or a point mostly red in colour and at the centre of the forehead between the eyebrows. A symbol to signify cosmos the understanding is that it retains energy and strengthens concentration.

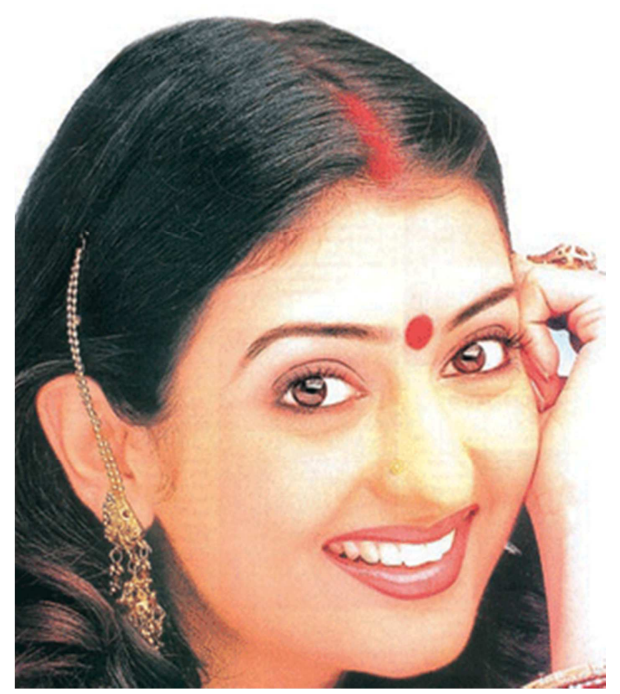

Figure 4. Bindi a signifier of the married women is supposed to symbolise cosmos and brings power for women. [11].

Tikuli or the art of making intricate bindi for the women of the rich nobility is basically a symbol of the feminine power. It is also referred to the practice of tikuli craft in the regions of Bihar.

Then there is the use of vermilion on the face right from the middle parting of the hair up till down to the nose, especially during chath, the most important festival of Bihar having roots in agrarian society. It is a marker for married women put on them by their husbands first on the wedding day.

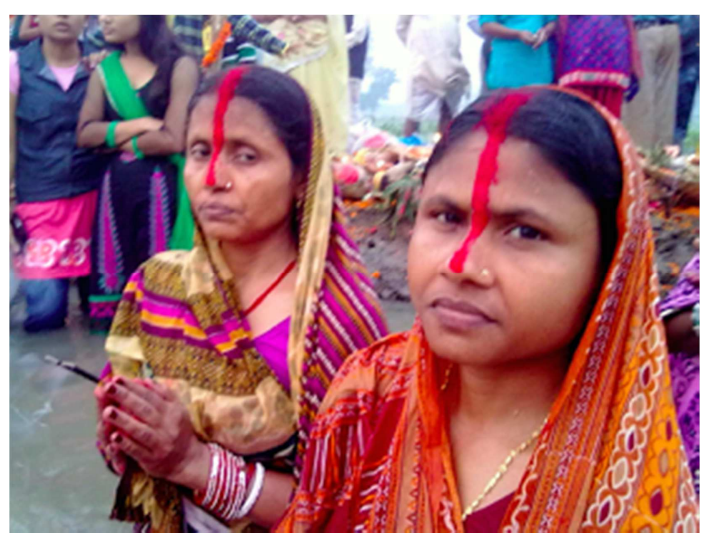

Figure 5. The vermilion mark or sindoor, mostly seen during the Bihari festival like chath is marker for prosperity and the married women. [12].

Another very prevalent form of decoration is on the feet and hands with the use of red coloured alta denoting blood or the sign of fertility. It is done as marker for married women mostly during marriages as part of one of the stages of solah shrigar and then later at various religious and festive rituals and ceremonies. Most of such elements of adornment applied by married women very definitively situate them in the patriarchal set up as objects of the male domination. It clearly shows that men who do not have to adhere to or abide by any such socio cultural codes or norms to be represented as married. This underlines the subjugation and the lower status of women in society, nevertheless these elements definitely give these women a definitive look and aesthetic appeal specific to the environment and culture of Bihar.

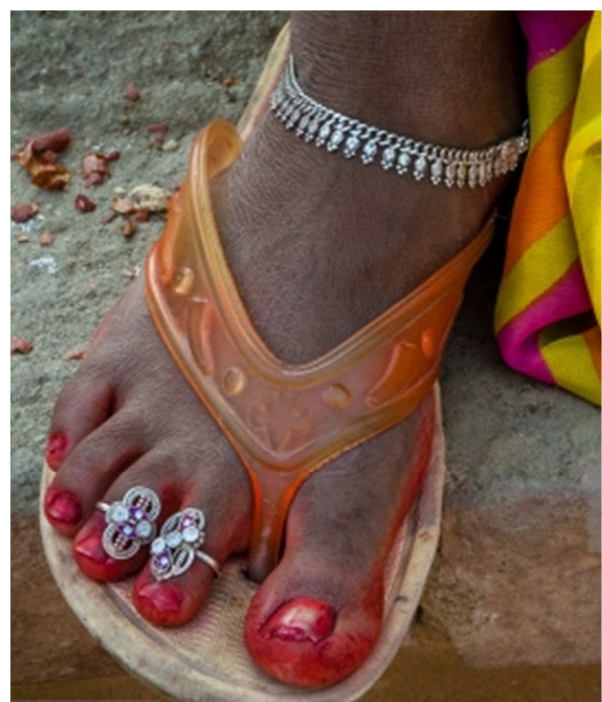

Figure 6. Alta denoting blood or the sign of fertility or prosperity is a symbol of married women. [13].

The amalgam of women adornment will not be complete without the mention of godna of Bihar. Godna or body tattoo has been used by women of the lower castes as a tool for protection from the upper caste men. It was also done as a signifier of women form the lower caste in a society with societal norms for class and caste.

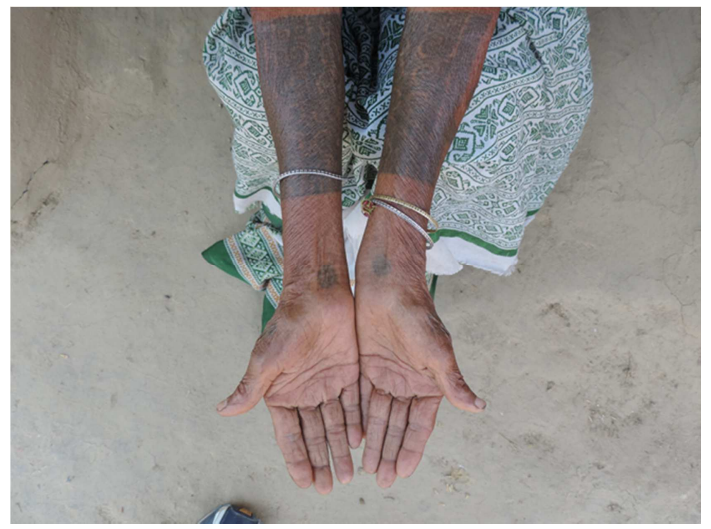

Figure 7. This is an example of godna, a style of tattoo prevalent in the lower caste women. [14].

The discussion on the material and craft culture of Bihar significantly includes to its list the practice of the recycling sustainable craft of sujni practiced by the women folk in the precincts of Muzzafarpur. Essentially to create a form of covering for babies it was made by placing together discarded pieces of clothes, sewn together and the motif made to create narrative of village life and the issues of 
women, bearing a resemblance to kantha of Bengal.

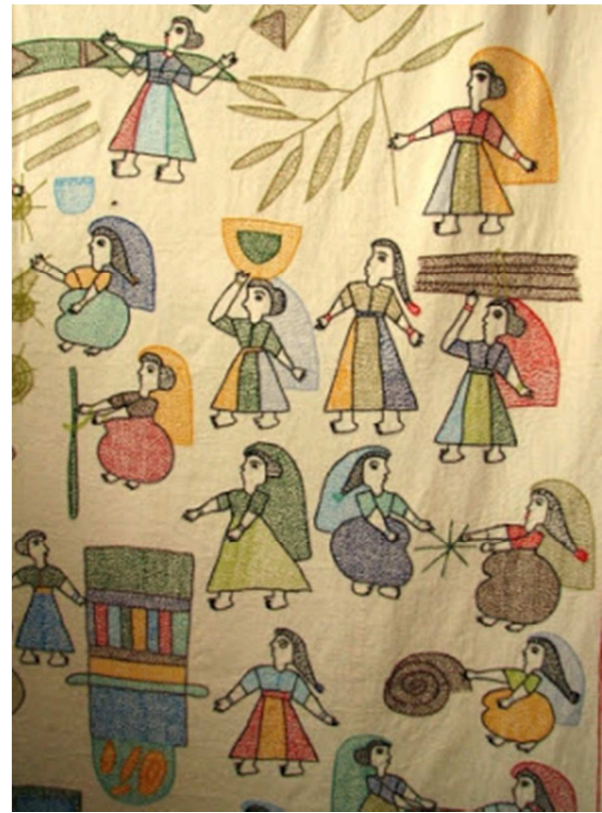

Figure 8. An example of sujni bed cover. Sujni is a craft practiced by women community depicting their issues. [15].

\section{Conclusion}

The specific cultural identity of Bihar is the basis on which development and evolution of the sets of people happen. These socio-cultural environment in certain time and space influence the people of any region and in the context of this article the state of Bihar by rendering to these sets of people a certain sense of distinctive array of values, beliefs, customs, adornment, dress, make up thus leading to the emergence of certain urban tribes or sections of people. The Bihari society is deeply entrenched in patriarchy, though it is not to be contested that there have been some dalit women movements from the lower echelons of society. The adornments and costumes among women have largely remained symbols of patriarchal control and have continued to carry their patriarchal connotation till now. However, it is not to be denied, that these adornments have also evolved into a distinct cultural identity of Bihari women. It is well evidenced by the fact that with due course, when these native, ethnic Bihari cultural symbols became an accepted set of material culture, they were appropriated by the current fashion system and by national brands like Fab India, Anokhi, fashion designers, and they get disseminated to the larger mass of humans over the nation and then the globe. These forms of material culture were taken up, through academic endeavors, by institutions like National Institute of Fashion Technology and by NGO's to work on the area of academia and development in context of the region of Bihar by understanding the prominence of regional and transnational aspect of it.

It is taken further by the breaking up of the notion of Euro centricism as discussed by Arif Dirlik in his article titled "Is their History after Euro centricism ? Globalism,
Postcolonialism and the disavowal of History". It is a common synthesised understanding of Euro centred fashion being futile as fashion has broken this barrier and gone on to a realm where homogenisation of fashion is in a way not only transforming it but also is also making it more localised and therefore diversified [2]. The article brings to fore this aspect of fashion which is accepting of more democratisation and the monopoly of the western paradigms of fashion as a system is disintegrating.

\section{References}

[1] A. K. Coomaraswamy, "Ornament," The Art Bulletin, vol 21, pp. 375-382, December 1939.

[2] A. Dirlik, "Is their HIstory after Eurocentricism?. Globalism, Postcolonialism, and the Disavowal of History, " Cultural Critique, vol 42, pp. 1-34, Spring 1999.

[3] A. K. Haldar, "Symbolism in Indian Art and culture, " The Journal of Aesthetics and Art Criticism, vol 9, pp. 124-127, 1950.

[4] D. N. Levine, Georg Simmel on Individuality and Social Forms (Heritage of Sociology Series) 1st Edition. Chicago, University of Chicago Press.

[5] E. Sapir, Language, An Introduction to the Study of Speech, New York Harcourt, Brace and Company.

[6] E. Tarlo, Clothing Matters, Dress and Identity in India, New York, University of Chicago Press.

[7] F. Davis, In: Fashion culture and identity. New York: University of Chicago Press. 1994, PP. 3-4.

[8] Figure 1 http://www.thehindu.com/news/national/otherstates/gandhigiri-keeps-a-train-running/article18192515.ece, accessed on 17/09/2017.

[9] Figure http://www.newindianexpress.com/nation/2016/nov/28/top-rjdleaders-missing-from-anti-demonetisation-protests-in-bihar1543488.html, accessed on 17/09/2017.

[10] Figure 3, http://lovemyartjewelry.blogspot.in/2012/12/toerings.html, accessed on 17/09/2017.

[11] Figure 4, http://imtamilandiknowit.tumblr.com, accessed on $17 / 09 / 2017$

[12] Figure 5, http://infospilledink.blogspot.in/2015/11/celebratingbeauty-of-bihar-chatt-puja.html, accessed on 18/09/2017.

[13] Figure 6, http://www.gettyimages.ae/detail/photo/close-up-ofindian-womans-feet-with-anklet-royalty-free-image/136115437, accessed on 18/09/2017.

[14] Figure 7, https://scroll.in/article/716615/from-marks-of-status-toa-kind-of-jewellery-tattoos-are-part-of-a-centuries-old-indiantradition, accessed on 18/09/2017.

[15] Figure 8, http://brindasuri.blogspot.in/2012/12/sujani-stitch-art-ofbihar.html, accessed on 18/09/2017.

[16] M. E. Roach-Higgins, and J. B. Eicher, "Dress and Identity," Clothing and Textile Research Journal, vol 10, pp. 1-8, June 1992. 
[17] N, Howe, and W. Strauss, Millenials Rising: The Next Great Generation. New York, Vintage, 3rd Printing Edition. 2000, pp. 4-10.

[18] R. Barnes, and J. B. Eicher, Dress and Gender, Making and Meaning. Paperback ed. New York, Berg Publisher, 1997, pp $198-204$.

[19] S. B. Kaiser, Fashion and Cultural Studies, New York. Berg. 1.
[20] S. Jha, Charkha," 'Dear Forgotten Friend' of Widows: Reading the Erasures of a Symbol, " Economic and Political Weekly, vol 39, pp. 3113-3120, July 2004.

[21] V. Bahl, " Shifting boundaries of Nativity and Moernity in South Asian Women's Clothes," Dialectical Anthropology, vol 29, pp. 85-121, March 2005. 